10,1

\title{
Свойства движущихся дискретных бризеров в бериллии
}

\author{
(C) О.В. Бачурина ${ }^{1}$, Р.Т. Мурзаев ${ }^{2}$, А.С. Семенов ${ }^{3}$, Е.А. Корзникова ${ }^{2}$, С.В. Дмитриев ${ }^{2,4}$ \\ ${ }^{1}$ Уфримский государственный нефтяной технический университет, \\ Уфра, Россия \\ ${ }^{2}$ Институт проблем сверхпластичности металлов РАН, \\ Уфра, Россия \\ ${ }^{3}$ Политехнический институт (филиал) ФГАОУ ВО \\ „Северо-Восточный фредеральный университет имени М.К. Аммосова“, \\ Мирный, Россия \\ ${ }^{4}$ Национальный исследовательский Томский государственный университет, \\ Томск, Россия \\ E-mail: obachurina@yahoo.com
}

(Поступила в Редакцию 23 ноября 2017 г.)

Дискретные бризеры (ДБ) были описаны в ряде чистых металлов с ГЦК- и ОЦК-решеткой, однако для ГПУ-металлов их свойства мало изучены. В настоящей работе при помощи метода молекулярной динамики с использованием многочастичного межатомного потенциала анализируются свойства стоячих и движущихся ДБ в ГПУ-металле бериллии. Показано, что ДБ локализован в плотноупакованном атомном ряду в базисной плоскости, при этом, колебания с большой амплитудой вдоль плотноупакованного ряда совершают два-три атома, двигаясь в противофазе с ближайшими соседями. Получены зависимости частоты ДБ от амплитуды, а также скорости движения ДБ от его амплитуды и от параметра $\delta$, определяющего разность фаз колебаний соседних атомов. Максимальная скорость движения ДБ в бериллии достигает $4.35 \mathrm{~km} / \mathrm{s}$, что составляет $33.7 \%$ от скорости продольных звуковых волн. Полученные результаты дополняют наши представления о механизмах локализации и транспорта энергии в ГПУ-металлах.

Работа выполнена при финансовой поддержке Российского научного фонда (грант № 16-12-10175) и Российского фонда фундаментальных исследований (грант № 17-02-00984).

DOI: 10.21883/FTT.2018.05.45798.334

\section{1. Введение}

Дискретными бризерами (ДБ) называются пространственно локализованные высокоамплитудные колебательные моды, которые могут существовать в бездефектной кристаллической решетке [1]. Имеются экспериментальные работы по изучению ДБ в кристаллах [2-10]. Однако известные технические трудности, связанные с постановкой таких экспериментов, в исследованиях свойств ДБ выдвигают на первый план методы атомистического моделирования. Например, метод молекулярной динамики, основанный на применении эмпирических межатомных потенциалов, позволил обнаружить и подробно изучить свойства ДБ в кристаллах различных типов [11-51]. Более точным является метод первопринципного моделирования, основанный на теории функционала плотности, который не требует предположений о межатомных потенциалах $[51,52]$.

Стоит отметить, что в реальных кристаллах ДБ не обладают точной периодичностью колебаний и, строго говоря, должны именоваться квазибризерами [11]. Изучению ДБ в нелинейных дискретных системах и, в частности, в кристаллах посвящен ряд обзоров [12-14].

Изучение нелинейных колебаний кристаллической решетки в реакторных материалах, в частности, бериллия, представляет особый интерес, поскольку они могут влиять на их свойства. В настоящее время бериллий рассматривается как материал первой стенки токамака в строящемся экспериментальном термоядерном реакторе ITER [53]. В результате реакции термоядерного синтеза образуются высокоэнергетические частицы, которые напрямую взаимодействуют с первой стенкой. С другой стороны, бериллий планируется использовать в качестве размножителя нейтронов, то есть увеличивать число последних при попадании в его ядра нейтронов, возникающих при реакции синтеза дейтерия и трития [54]. При таких условиях частицы высокой энергии вызывают значительные смещения атомов из положений равновесия, что, в свою очередь, может привести к возбуждению высокоамплитудных ДБ.

Отметим, что экспериментальное обнаружение ДБ, особенно в реакторных материалах, является довольно сложной задачей с технической точки зрения. В то же время существует ряд экспериментально наблюдаемых явлений, которые могут быть объяснены при помощи концепции ДБ.

Целью настоящей работы является выявление условий существования и характеристик покоящихся и движущихся ДБ в чистом ГПУ-бериллии в широком интервале амплитуд. Данное исследование является продолжением работы [55], где была показана возможность существования движущихся ДБ в чистом бериллии. 


\section{2. Методика компьютерного моделирования}

Молекулярно-динамические расчеты проводились с использованием пакета программ LAMMPS [56]. Для описания межатомного взаимодействия в бериллии был взят многочастичный потенциал, построенный на основе метода погруженного атома [57,58].

Равновесные постоянные кристаллической решетки для ГПУ-бериллия оказались равными $a=2.36 \AA$ и $c=3.70 \AA[57,58]$, что несколько выше их экспериментальных значений $a=2.29 \AA$ и $c=3.58 \AA$ [59].

Для моделирования была выбрана расчетная ячейка, содержащая $30 \times 10 \times 10$ элементарных ячеек (12000 атомов), что соответствует размеру $68.58 \times 39.59 \times 38.86 \AA$ (см. рис. 1). Тестовые расчеты показали, что использование расчетных ячеек бо́льшего размера приводит к тем же самым результатам, что связано с достаточно высокой степенью пространственной локализации исследуемых нелинейных колебательных мод. Периодические граничные условия были наложены вдоль всех трех координатных направлений. Все расчеты проводились при температуре $T=0 \mathrm{~K}$ с применением термодинамического ансамбля NVE (постоянное число атомов, объем и энергия).

Возбуждение ДБ осуществлялось в центре расчетной ячейки вдоль плотноупакованных атомных рядов [23], которые в ГПУ металлах лежат в базисной плоскости и имеют кристаллографическое направление [2 $\overline{1} \overline{1} 0]$. Атомы ряда, в котором возбуждался ДБ, нумеровались индексом $n$ (рис. 1). Отметим, что при этом все другие атомы, лежащие вне выделенного плотноупакованного ряда, в начальный момент времени имели нулевые смещения и скорости.

Начальные условия для возбуждения ДБ в плотноупакованном атомном ряду были следующими [38]:

$$
\begin{gathered}
x_{n}(t)=(-1)^{n} \cdot P_{n} \cdot \cos \left[\omega t+\varphi_{0}+\delta\left(n-x_{0}\right)\right]+S_{n}, \\
y_{n}=0, \quad \dot{y}_{n}=0 .
\end{gathered}
$$

Здесь $\omega$ - частота ДБ, лежащая выше верхней границы фононного спектра кристалла, которая для бериллия

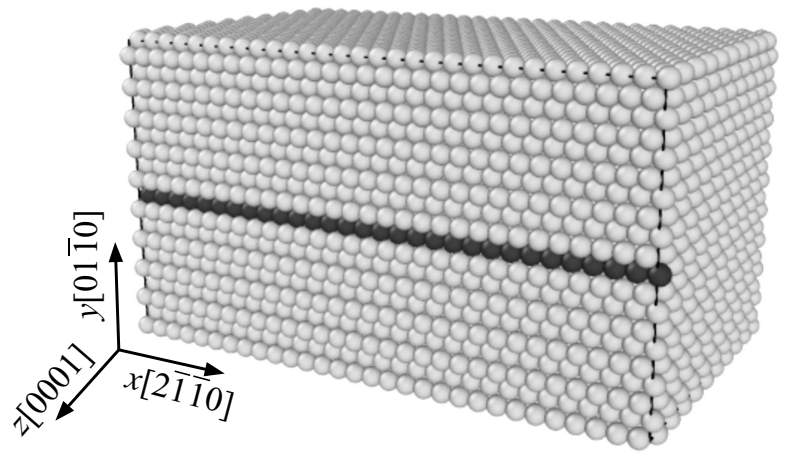

Рис. 1. Расчетная ячейка. ДБ возбуждались вдоль плотноупакованного ряда атомов (выделены светлым).

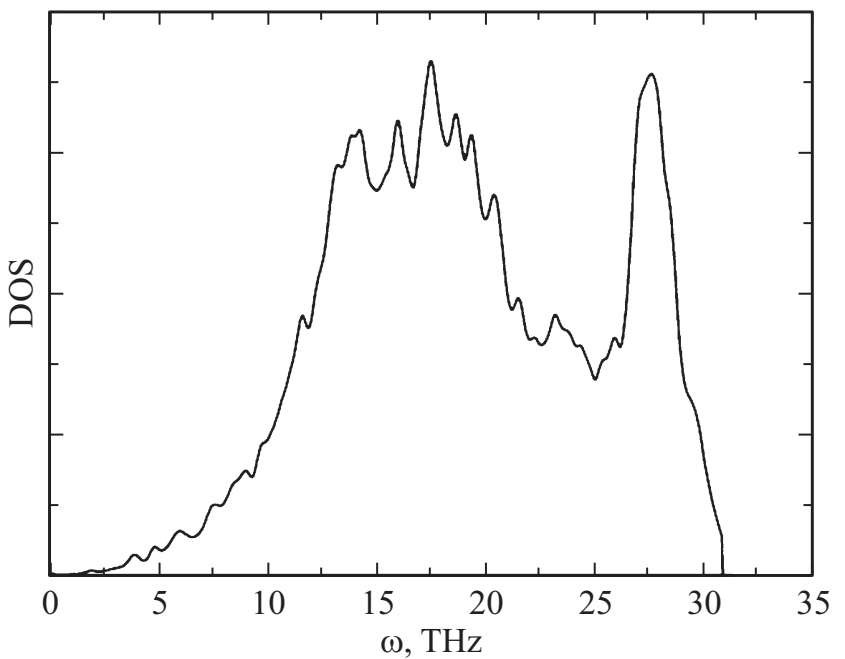

Рис. 2. Плотность фононных состояний, рассчитанная для берилия.

приблизительно равна $30.8 \mathrm{THz}$ (см. рис. 2); $\varphi_{0}-$ начальная фаза колебаний; $\delta$ - параметр, задающий разность фаз колебаний соседних атомов; функции $P_{n}$ и $S_{n}$ определяются выражениями:

$$
P_{n}=\frac{A}{\cosh \left[\beta\left(n-x_{0}\right)\right]}, \quad S_{n}=\frac{-B\left(n-x_{0}\right)}{\cosh \left[\gamma\left(n-x_{0}\right)\right]},
$$

где $A-$ амплитуда колебаний ДБ, $B$ - амплитуда смещений центров колебаний атомов, параметры $\beta$ и $\gamma$ задают степень пространственной локализации ДБ, а $x_{0}$ - начальное положение ДБ, которое может изменяться в пределах от 0 до 1 . При $x_{0}=0$ имеем ДБ центрированный на атоме, а при $x_{0}=1 / 2$ ДБ находится в середине между двумя соседними атомами. Скорость ДБ зависит от величины $\delta$, и при $\delta=0$ имеем неподвижный ДБ. Отметим, что такая же схема была ранее использована для возбуждения ДБ в металлах с ОЦК, ГЦК и орторомбической (альфа-уран) кристаллическими решетками [60-65].

Функции $P_{n}$ и $S_{n}$ в выражениях (2), описыващие соответственно амплитуды колебаний и смещения центров колебаний атомов, рассчитывались в ходе численного эксперимента следующим образом:

$$
P_{n}=\frac{\left(x_{n}^{\max }-x_{n}^{\min }\right)}{2}, \quad S_{n}=\frac{\left(x_{n}^{\max }+x_{n}^{\min }\right)}{2},
$$

где $x_{n}^{\max }$ и $x_{n}^{\min }-$ максимальное и минимальное значение (квази)периодической функции $x_{n}(t)$, описывающей движение $n$-го атома прямолинейного ряда, в котором был возбужден ДБ.

\section{3. Результаты моделирования}

3.1. Н еп одв и жны й ДБ. Возбуждение ДБ в бериллии производилось при следующих значениях параметров в выражениях (1) и (2): $A=0-0.65 \AA, B=0.1 \AA$, 

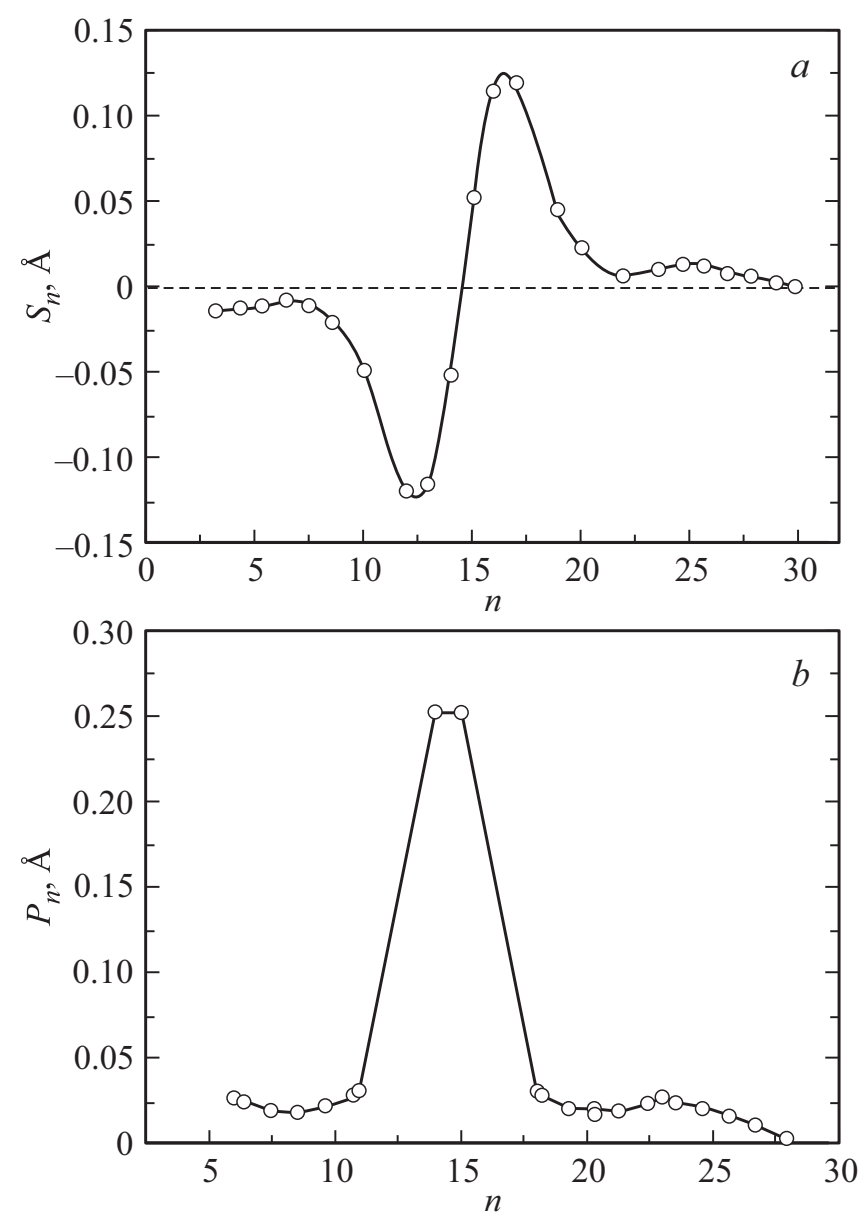

Рис. 3. Смещения центров колебания атомов $(a)$ и амплитуды колебания атомов $(b)$ ДБ в бериллии, возбужденного при помощи выражений (1) и (2) при следующих значениях параметров $A=0.35 \AA, B=0.1 \AA, \beta=0.6, \gamma=0.7, x_{0}=1 / 2$, $\delta=0$.

$\beta=0.8, \gamma=0.8, x_{0}=1 / 2, \delta=0-0.5$. Значение полученных амплитуд неподвижного ДБ (в случае, когда $\delta=0)$ лежит в пределах от 0.00016 до $0.223 \AA$ в интервале частот от 30.4 до $36.1 \mathrm{THz}$. Следует отметить, что при начальных амплитудах $A \leq 0.2 \AA$ и независимо от значений параметра $\delta$, возбуждения ДБ не происходит и после нескольких колебаний его энергия рассеивается по расчетной ячейке. При $A=0.25 \AA$ ДБ может существовать только в области $0<\delta \leq 0.25$, а при увеличении $\delta$ от 0.3 до 0.5 имеет место его затухание.

Графики зависимости амплитуды колебания атомов $P_{n}$ и смещения центров колебания атомов $S_{n}$ представлены на рис. 3. Видно, что у ДБ в бериллии большую амплитуду колебаний, $P_{n}$, имеют два или три атома, при центрировании ДБ на середине связи или на атоме соответственно. Статические смещения центров колебаний атомов, $S_{n}$, распространяются на 8-10 атомов. Из рис. 3 также видно, что максимальные смещения центров колебания атомов $S_{n}$ одного порядка со значениями максимальной амплитуды колебания $P_{n}$.
На рис. 4 показана зависимость частоты неподвижного ДБ $\omega$ от его начальной амплитуды $A$. Горизонтальной пунктирной прямой показана верхняя граница фононного спектра на уровне $30.8 \mathrm{THz}$. Видно, что частота колебания ДБ лежит выше фононного спектра, она сначала возрастает с увеличением амплитуды ДБ, но после достижения максимального значения $36.1 \mathrm{THz}$, начинает убывать при амплитудах выше $0.40 \AA$. Такое немонотонное поведение наблюдалось ранее для ДБ в металлах [66] и в кристаллах с ковалентной связью $[67,68]$. Это связано, прежде всего, с особенностями межатомного потенциала, а именно с тем, что при больших отклонениях от положения равновесия происходит уменьшение жесткости связи.

Зависимость установившейся амплитуды колебаний, $a$, от начальной, $A$, рассчитанная для различных

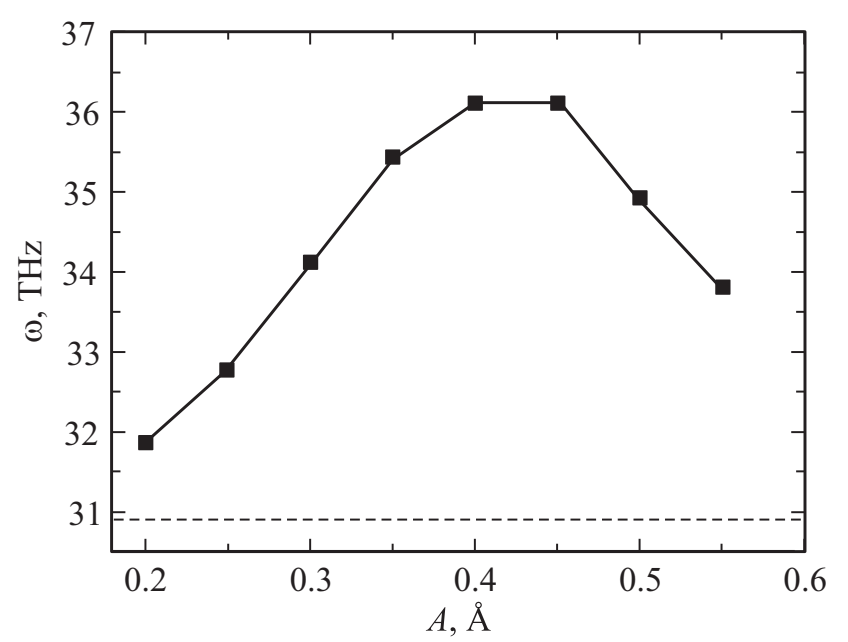

Рис. 4. Зависимость частоты ДБ в бериллии от начальной амплитуды колебаний $A$ при $\delta=0$ (неподвижный ДБ). Пунктиром показана верхняя граница фононного спектра, которая для бериллия приблизительно равна $30.8 \mathrm{THz}$

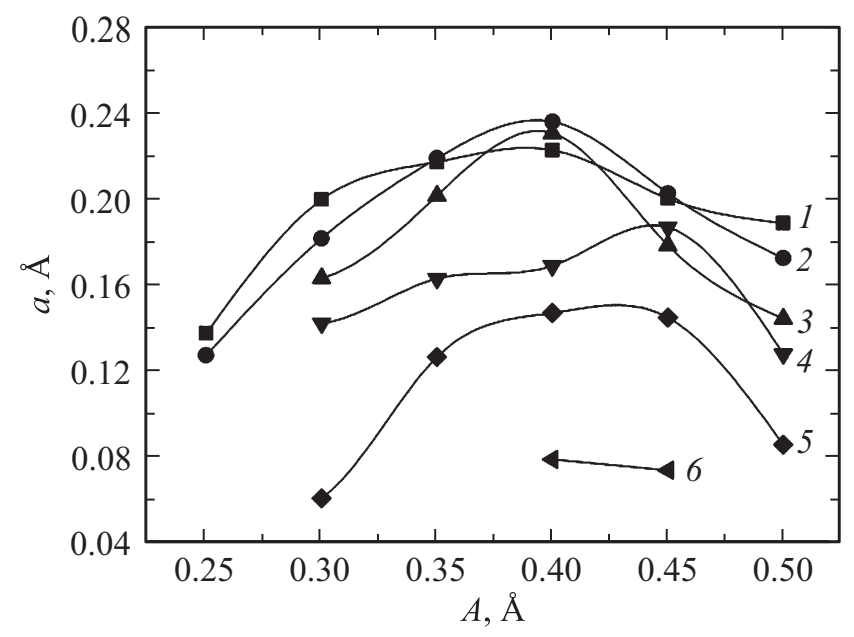

Рис. 5. Зависимость установившейся амплитуды колебаний ДБ, $a$, от начальной амплитуды, $A$, при различных значениях параметра $\delta$ : $\delta=0.05(1), \delta=0.15(2), \delta=0.25$ (3), $\delta=0.35(4), \delta=0.50(5), \delta=0.60(6)$. 
значений параметра $\delta$ представлена на рис. 5. Видно, что установившаяся амплитуда ДБ достигает своего максимума в пределах $0.37-0.40 \AA$ и затем начинает убывать вследствие рассеяния энергии на соседние атомы.

3.2. Подвижный ДБ. При значениях параметpa $\delta$ отличных от нуля, начальные условия (1) и (2) порождают движущийся ДБ. На рис. 6 представлены смещения атомов $n$ и $n+5, n+15$ вдоль координаты $x$ как функции времени, чтобы показать прохождение через них ДБ. Для возбуждения данного ДБ брались следующие значения параметров в выражениях (1) и (2): $A=0.30 \AA ; B=0.1 \AA ; \beta=0.8 ; \gamma=0.8 ; x_{0}=1 / 2$, $\delta=0.1$. Можно отметить факты смещения среднего положения атомов при прохождении через него ДБ и постепенного уменьшения амплитуды ДБ за счет излучаемых им малоамплитудных бегущих волн (фононов) (рис. 6). После прохождения ДБ атомы возвращаются в решеточные положения. Движущийся бризер достаточно быстро теряет свой начальный импульс и останавливается, пройдя несколько десятков межатомных расстояний. На рис. 6 также видно, что скорость ДБ уменьшается с падением его амплитуды. Причем для значений параметра $\delta$ от 0 до 0.15 имеет место более значительное падение скорости, в то время как для $\delta$ от 0.20 до 0.50 , уменьшение скорости выражено слабее.

Зависимость скорости движения ДБ от параметра $\delta$, определяющего разность фаз колебаний соседних атомов, представлена на рис. 7. Из рисунка видно, что скорость приблизительно линейно растет с увеличе-
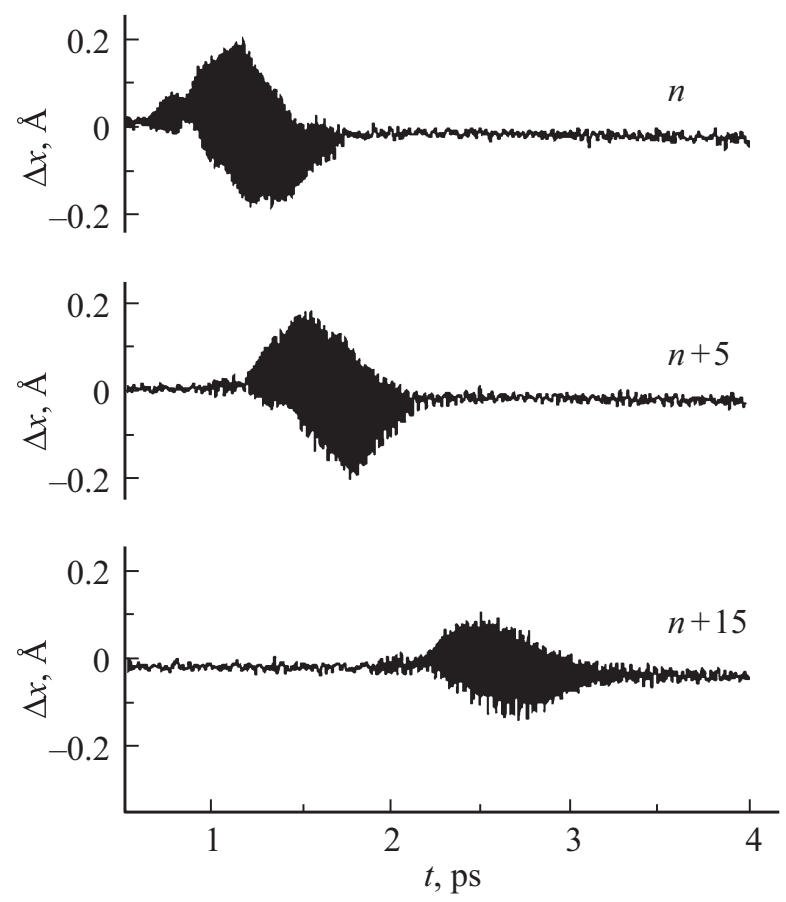

Рис. 6. Колебания атомов $n$ и $n+5, n+15$ в направлении оси $x[2 \overline{1} \overline{1} 0]$ при прохождении через них ДБ, возбужденного при следующих значениях параметров в выражениях (1) и (2): $A=0.30 \AA, B=0.1 \AA, \beta=0.8, \gamma=0.8, x_{0}=1 / 2, \delta=0.1$.

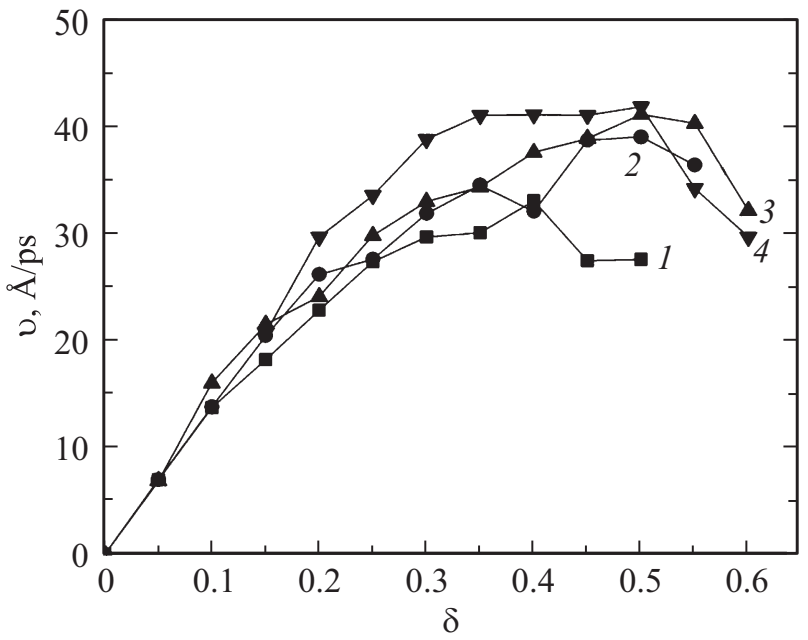

Рис. 7. Зависимость скорости ДБ в бериллии от параметра $\delta$, рассчитанная при различных значениях амплитуды: $A=0.30$ (1), $A=0.35$ (2), $A=0.40$ (3), $A=0.45$ (4).

нием параметра $\delta$, а затем выходит на насыщение. Максимальная скорость движения ДБ в бериллии достигается при значениях $A=0.5 \AA, \delta=0.30$ и равна $43.5 \AA / \mathrm{ps}(4.35 \mathrm{~km} / \mathrm{s})$, что составляет $33.7 \%$ от скорости продольного звука в бериллии, которая равна $12.9 \mathrm{~km} / \mathrm{s}$. Отметим, что авторами в работе [55] было получено несколько меньшее значение максимальной скорости для бериллия $(35 \AA / \mathrm{ps})$ ввиду того, что ими использовался другой набор параметров для возбуждения ДБ.

\section{4. Заключение}

Методом молекулярной динамики выявлены условия существования и характеристики движущихся ДБ в чистом ГПУ-бериллии в широком интервале амплитуд, в зависимости от разности фаз колебаний соседних атомов. Для возбуждения ДБ использовались начальные условия, определяемые выражениями (1) и (2), содержащими физически ясные параметры [38].

Выявлено, что в интервале начальных амплитуд ДБ, $A$, менее $0.20 \AA$ и при значениях параметра $\delta$ в интервале от 0 до 0.6, возбуждения ДБ не происходит. ДБ возбуждаются при более высоких значениях начальной амплитуды $A$. Частота ДБ лежит выше фононного спектра, сначала возрастает с ростом амплитуды ДБ, а затем начинает падать. Наибольшая частота ДБ составила $36.1 \mathrm{THz}$ при начальных амплитудах $A=0.4-0.45 \AA$ и $\delta=0$. При этом верхняя граница фононного спектра бериллия находится на уровне $30.8 \mathrm{THz}$.

Степень пространственной локализации ДБ достаточно велика. Смещения центров колебаний атомов локализованы примерно на восьми атомах одного плотноупакованного ряда, а большую амплитуду колебаний имеют лишь два или три атома, при центрировании ДБ на середине связи или на атоме соответственно. 
Начальные условия, задаваемые согласно выражениям (1) и (2), не являются точными, поэтому часть энергии, переданной кристаллу в начальный момент времени, рассеивается и установившаяся амплитуда ДБ, $a$, всегда меньше начальной амплитуды, $A$. Установившаяся амплитуда движущегося ДБ может лежать в диапазоне от 0.07 до $0.236 \AA$.

Рассчитана скорость движения ДБ в бериллии. Максимальное значение достигается при $A=0.5 \AA, \delta=0.30$ и составляет $43.5 \AA / \mathrm{ps}(4.35 \mathrm{~km} / \mathrm{s})$, то есть $33.7 \%$ от скорости продольного звука.

Полученные результаты показали, что движущиеся ДБ в бериллии характеризуются высокой стабильностью в интервале начальных амплитуд $A=0.25-0.50 \AA$ и параметра $\delta$ в интервале от 0.05 до 0.6.

В качестве продолжения исследования локализованных нелинейных возбуждений в бериллии и других ГПУ-металлах, в последующих работах предполагается изучение движения сверхзвуковых N-краудионов [69] и бризерных краудионов [70].

\section{Список литературы}

[1] A.J. Sievers, S. Takeno. Phys. Rev. Lett. 61, 970 (1988).

[2] B.I. Swanson, J.A. Brozik, S.P. Love, G.F. Strouse, A.P. Shreve, A.R. Bishop, W.-Z. Wang, M.I. Salkola. Phys. Rev. Lett. 82, 3288 (1999).

[3] N.K. Voulgarakis, G. Kalosakas, A.R. Bishop, G.P. Tsironis. Phys. Rev. B 64, 020301 (2001).

[4] G. Kalosakas, A.R. Bishop, A.P. Shreve. Phys. Rev. B 66, 094303 (2002).

[5] D.K. Campbell, S. Flach, Y.S. Kivshar. Phys. Today 57, 43 (2004).

[6] M.E. Manley, A. Alatas, F. Trouw, B.M. Leu, J.W. Lynn, Y. Chen, W.L. Hults. Phys. Rev. B 77, 214305 (2008).

[7] M.E. Manley, M. Yethiraj, H. Sinn, H.M. Volz, A. Alatas, J.C. Lashley, W.L. Hults, G.H. Lander, J.L. Smith. Phys. Rev. Lett. 96, 125501 (2006).

[8] M.E. Manley, A.J. Sievers, J.W. Lynn, S.A. Kiselev, N.I. Agladze, Y. Chen, A. Llobet, A. Alatas. Phys. Rev. B 79, 134304 (2009).

[9] M. Kempa, P. Ondrejkovic, P. Bourges, J. Ollivier, S. Rols, J. Kulda, S. Margueron, J. Hlinka. J. Phys.: Condens. Matter 25, 055403 (2013).

[10] A.J. Sievers, M. Sato, J.B. Page, T. Rossler. Phys. Rev. B 88, 104305 (2013).

[11] G.M. Chechin, G.S. Dzhelauhova, E.A. Mehonoshina. Phys. Rev. E 74, 036608 (2006).

[12] S. Flach, A. Gorbach. Phys. Rep. 467, 1 (2008).

[13] С.В. Дмитриев. Письма о материалах 1, 2, 78 (2011).

[14] S.V. Dmitriev, E.A. Korznikova, Yu.A. Baimova, M.G. Velarde. Phys. Usp. 59, 446 (2016).

[15] S.A. Kiselev, A.J. Sievers. Phys. Rev. B 55, 5755 (1997).

[16] L.Z. Khadeeva, S.V. Dmitriev. Phys. Rev. B 81, 214306 (2010).

[17] А.А. Кистанов, С.В. Дмитриев. ФТТ 54, 8, 1545 (2012).

[18] А.А. Кистанов, С.В. Дмитриев. Письма в ЖТФ 39, 13, 78 (2013).
[19] А.А. Кистанов, Ю.А. Баимова, С.В. Дмитриев. Письма в ЖТФ 38, 14, 72 (2012).

[20] Ю.А. Баимова, С.В. Дмитриев, А.А. Кистанов, А.И. Потекаев. Изв. вузов. Физика 56, 2, 60 (2013).

[21] С.В. Дмитриев, Ю.А. Баимова. Письма в ЖТФ 37, 10, 13 (2011).

[22] N.K. Voulgarakis, G. Hadjisavvas, P.C. Kelires, G.P. Tsironis. Phys. Rev. B 69, 113201 (2004).

[23] M. Haas, V. Hizhnyakov, A. Shelkan, M. Klopov, A.J. Sievers. Phys. Rev. B 84, 144303 (2011).

[24] A.V. Savin, Yu.S. Kivshar. Phys. Rev. B 85, 125427 (2012).

[25] T. Shimada, D. Shirasaki, T. Kitamura. Phys. Rev. B 81, 035401 (2010).

[26] J.A. Baimova, S.V. Dmitriev, K. Zhou. Europhys. Lett. 100, 36005 (2012).

[27] L.Z. Khadeeva, S.V. Dmitriev, Yu.S. Kivshar. JETP Lett. 94, 539 (2011).

[28] E.A. Korznikova, J.A. Baimova, S.V. Dmitriev. Europhys. Lett. 102, 60004 (2013).

[29] E.A. Korznikova, A.V. Savin, Yu.A. Baimova, S.V. Dmitriev, R.R Mulyukov. JETP Lett. 96, 222 (2012).

[30] Л.З. Хадеева, С.В. Дмитриев, Ю.С. Кившарь. Письма в ЖЭТФ 94, 7, 580 (2011).

[31] П.В. Захаров, М.Д. Старостенков, Н.Н. Медведев, А.М. Ерёмин, А.В. Маркидонов. ФПСМ 11, 3, 388 (2014).

[32] П.В. Захаров, М.Д. Старостенков, А.М. Ерёмин, Е.А. Корзникова, С.В. Дмитриев. ФПСМ 11, 2, 260 (2014).

[33] М.Д. Старостенков, П.В. Захаров, Н.Н. Медведев. ФПСМ 8, 4, 40 (2011).

[34] Н.Н. Медведев, М.Д. Старостенков, П.В. Захаров, О.В. Пожидаева. Письма в ЖЭТФ 37, 3, 7 (2011).

[35] Н.Н. Медведев, М.Д. Старостенков, П.В. Захаров, А.В. Маркидонов. Письма о материалах 3, 34 (2013).

[36] Н.Н. Медведев, М.Д. Старостенков. Изв. вузов. Физика 55, $11-3,113(2012)$

[37] А.А. Кистанов, А.С. Семенов, Р.Т. Мурзаев, С.В. Дмитриев. ФПСМ 11, 3, 322 (2014).

[38] А.А. Кистанов, Р.Т. Мурзаев, С.В. Дмитриев, В.И. Дубинко, В.В. Хижняков. Письма в ЖЭТФ 99, 6, 403 (2014).

[39] A.A. Kistanov, S.V. Dmitriev, A.P. Chetverikov, M.G. Velarde. Eur. Phys. J. B 87, 211 (2014).

[40] А.А. Кистанов, С.В. Дмитриев, А.С. Семенов, В.И. Дубинко, Д.А. Терентьев. Письма в ЖТФ 40, 15, 58 (2014).

[41] А.А. Кистанов, А.С. Семенов, С.В. Дмитриев. ЖЭТФ 146, 4, 869 (2014).

[42] А.А. Кистанов. ФПСМ 11, 1, 9 (2014).

[43] А.А. Кистанов, А.С. Семенов, С.В. Дмитриев. ФПСМ 11, 2, 223 (2014).

[44] Н.Н. Медведев, С.В. Дмитриев, М.Д. Старостенков. ФПСМ 4, 3, 100 (2007).

[45] L.Z. Khadeeva, S.V. Dmitriev. Phys. Rev. B 84, 144304 (2011).

[46] С.В. Дмитриев, Л.З. Хадеева, А.И. Пшеничнюк, Н.Н. Медведев. ФТТ 52, 7, 1398 (2010).

[47] О.В. Пожидаева, С.В. Дмитриев, Н.Н. Медведев, Ю.В. Бебихов, А.В. Самсонов, М.Д. Старостенков. ФПСМ 4, 4, 102 (2007).

[48] С.В. Дмитриев, Л.З. Хадеева. ФТТ 53, 7, 1353 (2011).

[49] С.В. Дмитриев, Н.Н. Медведев, Р.Р. Мулюков, О.В. Пожидаева, А.И. Потекаев, М.Д. Старостенков. Изв. вузов. Физика 51, 8, 73 (2008). 
[50] B. Liu, J.A. Baimova, S.V. Dmitriev, X. Wang, H. Zhu, K. Zhou. J. Phys. D 46, 305302 (2013).

[51] I.P. Lobzenko, G.M. Chechin, G.S. Bezuglova, Y.A. Baimova, E.A. Korznikova, S.V. Dmitriev. Phys. Solid State 58, 633 (2016).

[52] G.M. Chechin, S.V. Dmitriev, I.P. Lobzenko, D.S. Ryabov. Phys. Rev. B 90, 045432 (2014).

[53] Л.Г. Голубчиков, Д.К. Курбатов. Вопросы атомной науки и техники 4, 80 (2004).

[54] Б.Н. Колбасов, А.А. Борисов, Н.Н. Васильев, В.М. Леонов, Г.Е. Шаталов, В.А. Беляков, Ю.С. Стребков. Вопросы атомной науки и техники 4, 3 (2007).

[55] А.С. Семенов, Р.Т. Мурзаев, А.А. Кистанов, Ю.В. Бебихов. ФПСМ 12, 1, 26 (2015).

[56] http://lammps.sandia.gov/.

[57] A. Agrawal, R. Mishra, L. Ward, K.M. Flores, W. Wind. Mod. Simul. Mater. Sci. 21, 8 (2013).

[58] A. Agrawal, R. Mishra, L. Ward, K.M. Flores, W. Wind. Mod. Simul. Mater. Sci. 23, 3 (2015).

[59] K.J.H. Mackay, N.A. Hill. J. Nucl. Mater. 8, 263 (1963).

[60] А.А. Кистанов, А.С. Семенов, Р.Т. Мурзаев, С.В. Дмитриев. ФПСМ 11, 3, 322 (2014).

[61] А.А. Кистанов, А.С. Семенов, Р.Т. Мурзаев, С.В. Дмитриев. ФПСМ 11, 4/2, 572 (2014).

[62] Р.Т. Мурзаев, Е.А. Корзникова, Д.И. Бокий, С.Ю. Фомин, С.В. Дмитриев. ФПСМ 12, 3, 324 (2015).

[63] А.С. Семенов, Р.Т. Мурзаев, А.А. Кистанов, Ю.В. Бебихов. ФПСМ 12, 1, 26 (2015).

[64] R.T. Murzaev, A.A. Kistanov, V.I. Dubinko, D.A. Terentyev, S.V. Dmitriev. Comp. Mater. Sci. 98, 88 (2015).

[65] R.T. Murzaev, R.I. Babicheva, K. Zhou, E.A. Korznikova, S.Y. Fomin, V.I. Dubinko, S.V. Dmitriev. Eur. Phys. J. B 89, 168 (2016).

[66] R.T. Murzaev, A.A. Kistanov, V.I. Dubinko, D.A. Terentyev, S.V. Dmitriev. Comp. Mater. Sci. 98, 88 (2015).

[67] N.K. Voulgarakis, G. Hadjisavvas, P.C. Kelires, G.P. Tsironis. Phys. Rev. B 69, 11, 113201 (2004).

[68] R.T. Murzaev, D.V. Bachurin, E.A. Korznikova, S.V. Dmitriev. Phys. Lett. A 381, 1003 (2017).

[69] S.V. Dmitriev, N.N. Medvedev, A.P. Chetverikov, K. Zhou, M.G. Velarde. Phys. Status Solidi RRL 11, 1700298 (2017).

[70] A.P. Chetverikov, I.A. Shepelev, E.A. Korznikova, A.A. Kistanov, S.V. Dmitriev, M.G. Velarde. Comp. Condens. Matter 13, 59 (2017). 